\title{
Multi-approach model for improving agrochemical safety among rice farmers in Pathumthani, Thailand
}

\author{
Buppha Raksanam ${ }^{1,2}$ \\ Surasak Taneepanichskul ${ }^{2}$ \\ Wattasit Siriwong ${ }^{2}$ \\ Mark Robson ${ }^{3,4}$ \\ 'Sirindhorn College of Public Health, \\ Trang, ${ }^{2}$ College of Public Health \\ Sciences, Chulalongkorn University, \\ Bangkok, Thailand; ${ }^{3}$ School of \\ Environmental and Biological Sciences, \\ Rutgers University, ${ }^{4}$ School of Public \\ Health, University of Medicine and \\ Dentistry of New Jersey, \\ New Brunswick, NJ, USA
}

This article was published in the following Dove Press journal:

Risk Management and Healthcare Policy

30 July 2012

Number of times this article has been viewed

\begin{abstract}
The large-scale use of agrochemicals has raised environmental and human health concerns. A comprehensive intervention strategy for improving agrochemical safety among rice farmers in Thailand is lacking. The objective of this study is to develop a model in order to improve farmers' health and prevent them from being exposed to agrochemical hazards, in addition to evaluating the effectiveness of the intervention in terms of agrochemical safety. This study was conducted between October 2009 and January 2011. It measures changes in the mean scores of agrochemical knowledge, health beliefs, agrochemical use behaviors, and in-home pesticide safety. Knowledge of agrochemical use constitutes a basic knowledge of agrochemicals and agrochemical safety behaviors. Health beliefs constitute perceived susceptibility, severity, benefits, and barriers to using agrochemicals. Agrochemical use behaviors include self-care practices in terms of personal health at specific times including before spraying, while spraying, during storage, transportation, waste management, and health risk management. Fifty rice farmers from Khlong Seven Community (study group) and 51 rice farmers from Bueng Ka Sam community (control group) were randomly recruited with support from community leaders. The participants were involved in a combination of home visits (ie, pesticide safety assessments at home) and community participatory activities regarding agrochemical safety. This study reveals that health risk behaviors regarding agrochemical exposure in the study area are mainly caused by lack of attention to safety precautions and the use of faulty protective gear. After 6 months, the intervention program showed significant improvements in the overall scores on knowledge, beliefs, behaviors, and home pesticide safety in the study group $(P<0.05)$. Therefore, this intervention model is effective in improving agrochemical safety behaviors among Khlong Seven Community rice farmers. These findings demonstrate that a multi-approach model for improving agrochemical safety behaviors can lead to sustainable prevention of agrochemical hazards for farmers.
\end{abstract}

Keywords: rice farmer, agrochemical safety, community-based intervention, model

\section{Introduction}

Farmers face various occupational health hazards, including health effects from agrochemical exposure (ie, pesticide exposure), musculoskeletal problems, and injuries. ${ }^{1}$ Pesticide exposure is a particularly high occupational risk among farmers in Thailand, ${ }^{1,2}$ and pesticides are widely used throughout the world to protect or promote industrial agricultural products. Pesticides not only destroy pests, but can also damage the surrounding ecosystem and other living organisms necessary for maintaining ecological balance. ${ }^{2-4}$ Organophosphates and carbamates are the most common agrochemicals in the Klong Seven community. ${ }^{1}$ Short-term exposure can cause irritation to the skin, eyes, and nose, and impair lung and visual functions. It can also affect memory and
Correspondence: Surasak

Taneepanichsakul

College of Public Health Sciences,

Chulalongkorn University, Bangkok

10330, Thailand

Email surasak.t@chula.ac.th 
cause liver, kidney, and stomach discomfort and aplastic anemia. Both short- and long-term exposure can affect the nervous system..$^{3-14}$ Several studies have found that farmers are at elevated risk for various cancers, which is related to their exposure to pesticides. ${ }^{14}$ The need for large amounts of pesticides has raised human health and environmental concerns. The total morbidity rates of pesticide poisoning in Thailand in 2006, 2007, and 2008 were 15.9, 18.3, and 14.7 per 100,000 persons, respectively. ${ }^{15}$ Morbidity rates associated with organophosphate and carbamate-use represent the highest rates of poisoning among farmers (8.0, 7.6, and 6.6 per 100,000 persons, respectively). ${ }^{15}$

This study was conducted in Khlong Seven community, in the Klong Luang district, of Pathumthani province, in Thailand. This community is situated on the Chao Phraya river basin, and is surrounded by numeros canals. Rice farmers living in the Khlong Seven community are often not aware of agrochemical safety, especially in their work places and homes. They may not understand the potential adverse effects of pesticide use on their families' health. Furthermore, ecological risks and contamination of human food sources from organochlorines were found in this area. ${ }^{16}$

The Bueng Ka Sam rice farmers were recruited as a control group using the purposive sampling method, and were selected for the similarity of their cultivated land and their year-round growing season. The Bueng Ka Sam community is a subdistrict of Nong Suea district, in Pathumtani province. It is also situated on the Chao Phraya basin near plenty of canals and plantations. Health risk problems associated with agrochemical exposure, especially pesticide, exposure were found in this area.

This study applied the health belief model and community participatory approach to develop a comprehensive strategy for improving health and safety behaviors associated with agrochemical exposure. The study focuses on farmers' perceived susceptibility, severity, benefits, and barriers related to decisions about whether to take action on environmental health concerns regarding agrochemical exposure. ${ }^{17-20}$ Community involvement in environmental health is a participatory approach to health care that is organized from the perspective of the farmer recipients. The participation of community members in the development of the health model increases the likelihood that it will be culturally appropriate and that its format and content will fit the community's cultural system. ${ }^{21-23}$

Since a comprehensive model for improving agrochemical safety among rice farmers in Thailand is lacking, an innovative community-based intervention program related to agrochemical safety behavior is needed. The study objectives are to develop a model to improve farmers' health and prevent agrochemical hazards, as well as to evaluate the effectiveness of intervention programs regarding agrochemical safety behaviors among rice farmers in the Khlong Seven community.

\section{Materials and methods Research procedure}

This study was conducted in the Khlong Seven community between October 2009 and January 2011. The study was designed to maximize internal validity (confidence in causeand-effect conclusions) despite our inability to randomize samples. The study was designed to reduce confounding variables as much as possible, given that random assignment was not available. The eligibility criteria of the respondents included rice farmers who lived in the Khlong Seven community, who had used agrochemicals for at least one year, and who were willing to participate in the study. Fifty rice farmers from the Khlong Seven community (study group) and 50 rice farmers from the Bueng Ka Sam community (control group) were randomly recruited. Data collection was completed using a combination of quantitative and qualitative methods. The research procedure was divided into three phases: (1) the preparatory phase, (2) the pre-implementation phase, and (3) the implementation and evaluation phase (hereafter known as the intervention phase).

1. The preparatory phase included building connections, and conducting a community study, a cross-sectional survey, and a situation analysis. The objective of this phase was to analyze the factors affecting health safety and prevention of occupational agrochemical hazards among farmers in the Khlong Seven community.

2. The pre-implementation phase included recruiting participants, assessing the stakeholers' needs, designing the intervention model, identifying a responsible person for each activity, preparing training materials and instruments, and conducting a pilot project.

3. The intervention phase was a combination of three steps, including the first home visit, community-based participatory activities regarding agrochemical safety, and a second home visit.

New materials, such as agrochemical safety videos, picture booklets, flip charts, and posters, were developed using ideas from the Khlong Seven participants. These served as a guideline for introducing the idea of community involvement in environmental health as it relates to agrochemical safety. The materials were distributed to the participants who 
participated the community-based activities on agrochemical safety.

\section{Research instruments}

Five experts on environmental health, community health, behavior, and social science verified the content validity and reliability of the questionnaire. A pilot project was carried out in the Bueng Ka Sam community with 30 purposive sampling subjects. The effectiveness of the intervention program was monitored by the changes in the mean scores of knowledge, beliefs, behaviors, and an assessment of pesticide safety in the home. Therefore, the research instruments used for this study were questionnaires on (1) knowledge, (2) health beliefs, and (3) behaviors, as well as (4) an in-home pesticide safety assessment, and (5) a focus-group discussion.

1. The questionnaire on knowledge was concerned with basic knowledge of agrochemical safety behaviors. All of the 22 questions in this part were in multiple-choice format. Examples of the questions included:

- How are you exposed to agrochemicals, especially pesticides?

- What are the dangers of agrochemicals, especially pesticides?

- What are the most important points to consider when choosing agrochemicals?

- What should you do if the nozzle is clogged while you are spraying agrochemicals, especially pesticide?

- What is the disposal method for agrochemical containers?

2. The questionnaire concerning health beliefs was divided into four sections including perceived susceptibility, severity, benefits, and barriers to using agrochemicals. The 22 questions were scored on a five-point Likert scale, ranging between strongly agree, agree, uncertain, disagree, and strongly disagree. The questionnaire asked the participants to rate statements such as these:

- Long-term exposure to agrochemicals, especially pesticides can affect the nervous system.

- Used pesticide containers can be washed and reused for cooking.

- Someone who is allergic to agrochemicals may experience potentially dangerous complications of other diseases.

- For your safety, you should always read agrochemical instructions before use.

- To reduce the risk of exposure to agrochemicals, especially pesticides, you should spray in the same direction as the wind.
3. The questionnaire concerned with behaviors was divided into two sections of 20 questions specifically on self-care practices before, during, and after handling agrochemicals. The participants were asked to choose from a four-point Likert scale ranging between always, often done, sometimes done, and never done. Examples of use behaviors include: checking tools and equipment before working; using expired agrochemicals; leaving food near or in the spraying area; conducting a breathing test to determine whether an agrochemical is real or fake; discarding empty or expired containers in regular disposal areas; storing agrochemicals in a locked area.

4. The in-home safety assessment identified the safety of behaviors in and around the home. The participants answered twelve questions with "yes" or "no." Examples of these questions included:

- Do you leave agrochemicals in the bathroom?

- Do you leave agrochemicals in the kitchen?

- Do you store agrochemicals in a locked room?

- Do you separate your waste into hazardous trash and general trash?

- Do you have the telephone numbers of hospitals, health centers, and toxicological centers in case of a hazardous agrochemical emergency?

5. The focus group explored agrochemical use in the Khlong Seven community, environmental health risks related to agrochemical exposure, and recommendations for guidelines to improve pesticide safety in the Khlong Seven community. Examples of the focus group discussion guidelines included:

- What belief systems influence farmers' perceived risks of agrochemical exposure?

- What are farmers' beliefs regarding the severity, susceptibility, barriers, and benefits of agrochemical exposure?

- What observed work-related and socio-cultural factors modify agrochemical exposure risks?

- What do farmers need to improve agrochemical safety in the Khlong Seven community?

- How can guidelines be established to improve agrochemical safety in Khlong Seven?

\section{Ethical considerations}

This study was approved according to the Chulalongkorn University Ethics Committee review guidelines for the protection of human subjects (Protocol No 041.2/53). Numbers and codes were used during the data collection phase to ensure that the data remained confidential. Furthermore, written 
informed consent was obtained from the participants prior to conducting any study-related procedures.

\section{Intervention model}

The intervention program was a combination of three steps including a first home visit, community-based participatory activities, and a second home visit.

The first home visit involved identifying environmental hazards in terms of agrochemical risk in and around the home, as well as educating farmers on agrochemical safety and other observed environmental health and home safety issues. The pretest questionnaires were administered in this phase. At the end of the first visit, a Home Pesticide Safety Checklist was placed in a prominent position in the home. All participants were invited to attend the community participatory activities on agrochemical safety behaviors.

The community-based participatory activities involved discussions on priorities identified during the first home visit. These priorities were related to agrochemical safety such as safe handling and use of agrochemicals, pesticide poisoning and management, and hands-on learning. The participants attended six monthly meetings, and received individual visits from the research team for assistance with safer storage of agrochemicals. Discussions on improving hygiene practices, such as post-application practices and washing contaminated clothing also took place. The research team comprised public health experts, healthcare workers, nurses, and healthcare volunteers who had experience working and living in the study area. Popular education techniques such as a mixed-media format were used by incorporating directed discussion, in-depth interviews, focus group discussions, and role-playing. For example, an agrochemical safety behavior drawing contest was included in this phase. After the community-based participatory activities were completed, the participants completed a post-test with the research team at their home during their second visit.

The second home visit involved observing the farmers' behavior changes and their ability to reduce the risk of agrochemical exposure within their home. The second home visit was performed 6 months after the initial visit. In addition, a problem-solving discussion regarding agrochemical safety and other health-related agrochemical issues arose.

\section{Data analysis}

Quantitative data were analyzed using descriptive statistics. Frequencies and percentages were used for demographic, occupational data, and the in-home pesticide safety assessment. Mean and standard deviation were used to determine the scores for the knowledge, beliefs, behaviors questionnaires, and the in-home pesticide safety assessment. An independent sample $t$-test and chi square were used to compare the scores between the study and control groups from the knowledge, beliefs, and behaviors questionnaires, and the in-home pesticide safety assessment. A paired sample $t$-test was used to compare changes in the participants' pre-test and post-test scores within the study and control groups.

The qualitative data were analyzed using content analysis. The content analysis was conducted by systematically organizing and interpreting information using categories, themes, and motifs that revealed patterns and relationships.

\section{Results}

The baseline comparisons of the demographic characteristics between the study and control groups were not significantly different $(P>0.05)$. The majority of the participants $(54.5 \%)$ were male. The average age was 49.91 years. The age range of the sample was $22-60$ years. Most of the participants $(72.30 \%)$ were married and had obtained a primary-level education (55.4\%). The average income was 6,702.97 baht per month. Most participants $(66.30 \%)$ rented the farms where they worked; some $(23.2 \%)$ owned the land for farming; and the others owned their farms and rented out areas to other farmers. Most had been involved in agricultural labor for an average of 20.48 years (Table 1).

Rice-farming is a primary occupation in the Khlong Seven community. During the farming season, most of the participants spent 10-12 hours per day, seven days a week, throughout all seasons. They also worked as laborers in the factories in Pathumthani or Bangkok during the off-seasons. An agrochemical backpack sprayer was the most common application method for pesticides in the Khlong Seven community.

This study reveals the major factors related to health risk behaviors through agrochemical exposure in the Khlong Seven community. These factors result from the misuse of pesticides through the erroneous beliefs of farmers about pesticide toxicity, lack of attention to safety precautions, environmental hazards, information about first-aid and antidotes provided by the label, use of faulty spraying equipment or lack of proper maintenance of spraying equipment, and lack of protective gear and appropriate clothing while handling pesticides. Most of the participants used agrochemical products containing organophosphate pesticide as the active ingredient, and the most popular brand name in the Khlong Seven community was Abamectin ${ }^{\circledR}$ (Crop Products Pvt Ltd., Bangkok, Thailand). The next most frequently used active ingredient was carbamate. Among the herbicides, glyphosate was the most frequently mentioned. 
Table I Demographic and socioeconomic characteristics of the participants and control groups

\begin{tabular}{|c|c|c|c|c|c|c|c|}
\hline \multirow[t]{2}{*}{ Characteristic } & \multicolumn{2}{|c|}{ Total $(n=10 I)$} & \multicolumn{2}{|c|}{ Study $(n=50)$} & \multicolumn{2}{|c|}{ Control $(n=5 I)$} & \multirow[t]{2}{*}{$P$ value } \\
\hline & $\mathrm{n}$ & $\%$ & $\mathbf{n}$ & $\%$ & $\mathbf{n}$ & $\%$ & \\
\hline \multicolumn{8}{|l|}{ Sex } \\
\hline Male & 55 & 54.50 & 27 & 54.0 & 28 & 54.9 & 0.543 \\
\hline Female & 46 & 45.50 & 23 & 46.0 & 23 & 45.1 & \\
\hline Age (years) mean $\pm S D$ & \multicolumn{2}{|c|}{$44.91 \pm 10.29$} & \multicolumn{2}{|c|}{$44.86 \pm 10.39$} & \multicolumn{2}{|c|}{$44.96 \pm 10.31$} & 0.960 \\
\hline \multicolumn{7}{|l|}{ Marital status } & 0.176 \\
\hline Single & 7 & 6.9 & 6 & 12 & 1 & 2 & \\
\hline Married & 73 & 72.3 & 36 & 72.0 & 37 & 72.5 & \\
\hline Widowed & 11 & 10.9 & 3 & 6.0 & 8 & 15.7 & \\
\hline Divorced & 7 & 6.9 & 4 & 8.0 & 3 & 5.9 & \\
\hline Separated & 3 & 3.0 & I & 2.0 & 2 & 3.9 & \\
\hline \multicolumn{7}{|l|}{ Education } & 0.545 \\
\hline Uneducated & 0 & 0 & 0 & 0 & 0 & 0 & \\
\hline Primary school & 56 & 55.4 & 31 & 62 & 26 & 51 & \\
\hline Secondary school (grade 7-9) & II & 10.9 & 2 & 4 & 8 & 15.7 & \\
\hline Secondary school (grade 10-12) & 20 & 19.8 & 10 & 20 & 10 & 19.6 & \\
\hline Certificate & 8 & 7.9 & 4 & 8 & 4 & 7.8 & \\
\hline Bachelor's degree & 4 & 4.0 & 2 & 4 & 2 & 3.9 & \\
\hline Other & 2 & 2 & 1 & 2 & 1 & 2.0 & \\
\hline Income (baht) mean \pm SD & \multicolumn{2}{|c|}{$6,702.97 \pm 2,099.02$} & \multicolumn{2}{|c|}{$6,830.00 \pm 2,406.64$} & \multicolumn{2}{|c|}{$6,578.43 \pm 1,761.74$} & 0.550 \\
\hline \multicolumn{8}{|l|}{ Type of farmland ownership } \\
\hline Renter & 63 & 66.3 & 31 & 70.5 & 32 & 62.7 & 0.210 \\
\hline Renter and owner & 10 & 10.5 & 2 & 4.5 & 8 & 15.7 & \\
\hline Owner & 22 & 23.2 & 11 & 25 & 11 & 21.6 & \\
\hline Missing data & \multicolumn{2}{|l|}{6} & \multicolumn{2}{|l|}{6} & & & \\
\hline $\begin{array}{l}\text { Duration of agricultural } \\
\text { occupation (years) mean } \pm S D\end{array}$ & \multicolumn{2}{|c|}{$20.48 \pm 13.19$} & \multicolumn{2}{|c|}{$20.38 \pm 13.29$} & \multicolumn{2}{|c|}{$20.58 \pm 13.22$} & 0.943 \\
\hline
\end{tabular}

Abbreviation: SD, standard deviation.

\section{Comparison of independent variables before and after intervention}

The baseline pre-test comparison of the mean scores of knowledge, beliefs, behaviors, and the in-home pesticide safety assessment between the study and control groups showed no significant difference. After 6 months of community-based intervention, there were significant differences in the scores of knowledge, belief, behavior, and the in-home pesticide safety assessment in the study group and control group $(P<0.05)$. The participants in the study group had significantly higher scores in knowledge, belief, behavior, and the in-home pesticide safety assessment than before they completed the intervention (Table 2).

\section{Comparison of dependent variables before and after intervention}

The mean scores in the study group between the pre-test and post-test significantly improved $(P<0.05)$. The participants in the study group had significantly higher scores in knowledge, beliefs, and behaviors, and the in-home pesticide safety assessment after receiving the intervention. The mean scores in the control group between the pretest and post-test showed no significant improvements $(P>0.05)$ (Table 2).

\section{Discussion}

Preventing agrochemical exposure and improving agrochemical safety behaviors are important public health concerns. Community involvement is an important means of solving environmental health problems. However, the participants were more concerned with their financial situation. This study found a significant improvement in the study group before and after completion of the program. The significantly improved results demonstrate the effectiveness of the intervention in the study group. These findings were consistent with Janhong et al's study, ${ }^{24}$ which found that the experimental group had significantly higher mean scores on knowledge, attitudes, and practices than before the intervention $(P<0.001)$. The overall mean scores between the pre-test and post-test in the control group showed no significant changes. The increase of some 


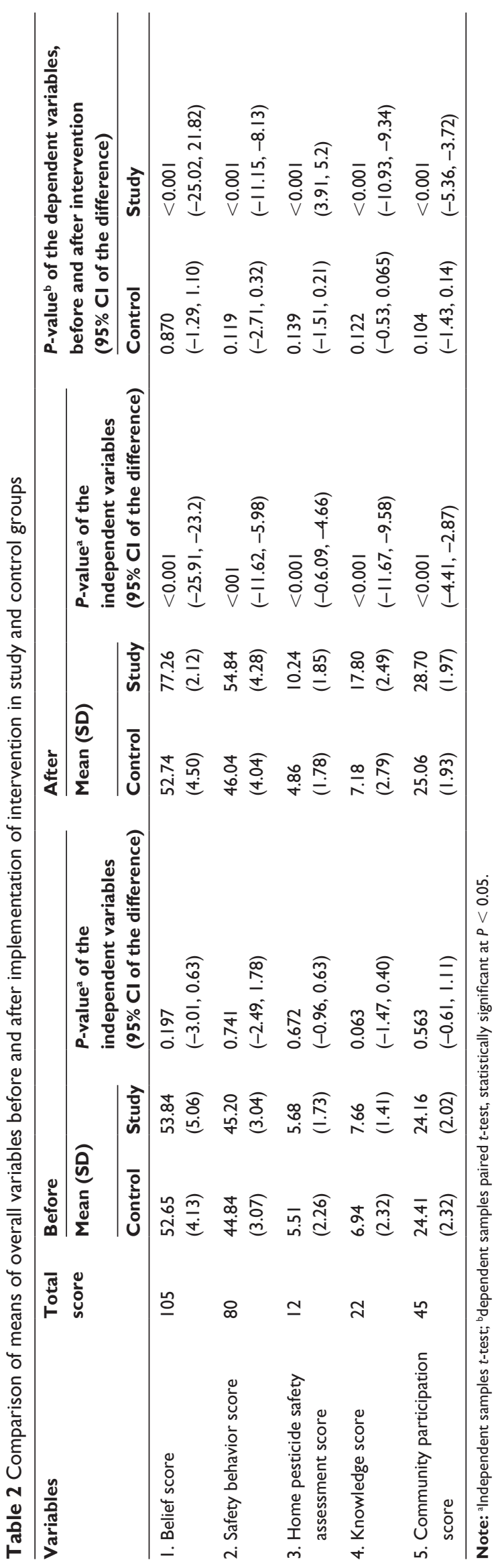


scores (eg, taking a bath immediately after crop-dusting with agrochemicals) may be affected by competing external influences, such as the mass media. It is equally as important to consider that some farmers work with their families, so it was difficult to be sure that the farmers in the control group were not receiving some aspects of the intervention from other sources. However, the safety behavior scores in the "before handling agrochemicals" section were not significantly improved, which implies that the participants needed more motivation and education specifically concerning practices or behaviors before handing agrochemicals.

Although the study was carefully designed using the most appropriate method with a control group and a pretest and post-test, it is necessary to interpret the results with caution since they may be affected by external factors such as previous experiences and a recall bias from the pre-test. Moreover, using the questionnaires to measure behaviors may not adequately portray actual behaviors. Qualitative approaches, such as observation, in-depth interviews, and focus-group discussions can provide additional aspects besides the information derived from the questionnaires. Furthermore, statistical significance obviously does not guarantee a measurable impact on pesticide exposure; therefore, the control group was necessary in this study. Further studies should include a biomarker assessment.

This study was conducted in the Khlong Seven community, in the Pathumthani province in Thailand. Other provinces were not selected for the study. Therefore, the results may not be representative of other rural populations with different agrochemical practices. Furthermore, community meetings were arranged to share the study's findings. It is necessary to work collaboratively with the Khlong Seven community partners and local authorities in order to sustain the intervention. It is possible to develop other educational materials to enable this process and to allow other communities to replicate this project. It is also necessary to work with local authorities and advocacy and community farmers to translate the results of the intervention into appropriate policy changes. By giving the community more ownership over agrochemical safety related projects, the Khlong Seven community has the capacity and commitment to operate and manage this project. When the community is closely involved with implementing the study project, they become active members of the project and share responsibility for the results and the effectiveness of the project.

\section{Conclusion}

The participants learned that potentially dangerous situations exist in the fields and their homes. The community gained knowledge and took the necessary steps to incorporate agrochemical safety recommendations for their families and community. In conclusion, this intervention model was effective in improving agrochemical safety behaviors among the Khlong Seven community rice farmers. This model can be applied with other vulnerable groups such as maize, orange, and chili farmers. However, beliefs and behaviors can be expected to vary across regions due to differences in origin and cultural diversity.

\section{Acknowledgments}

This research was financially supported by Sirindhorn College of Public Health, Trang, Thailand, the Thai Fogarty ITREOH Center (NIH FIC D43TW007849, NIEHS P30ES005022, NIEHS P32ES007148), and the thesis Scholarships for Students from Graduate School at Chulalongkorn University, Thailand. The authors wish to thank Dr David Robert for his editing assistance and all the participants in this study.

\section{Disclosure}

The authors declare no conflicts of interest with respect to the authorship and/or publication of this article.

\section{References}

1. Buranatrevedh S, Sweatsriskul P. Model development for health promotion and control of agricultural occupational health hazards and accidents in Pathumthani, Thailand. Ind Health. 2005;43(4):669-676.

2. Panuwet P, Siriwong W, Prapamontol T, et al. Agricultural pesticide management in Thailand: situation and population health risk. Environ Sci Policy. 2012;17:72-81.

3. World Health Organization, United Nations Environment Programme, WHO/UNEP Working Group on Public Health Impact of Pesticides Used in Agriculture. Public Health Impact of Pesticides Used in Agriculture. New York: World Health Organization; 1990.

4. Ecobichon DJ. Pesticide use in developing countries. Toxicology. 2001;160(1-3):27-33.

5. Weisenburger DD. Human health effects of agrichemical use. Hum Pathol. 1993;24(6):571-576.

6. Robson MG, Hamilton GC, Brachman GO. Case study on chronic organophosphate poisoning. New Solut. 2001;11(3):243-249.

7. Klein-Schwartz W, Smith G. Agricultural and horticultural chemical poisonings: mortality and morbidity in the United States. Ann Emerg Med. 1997;29(2):232-238

8. Keifer MC, Firestone J. Neurotoxicity of pesticides. J Agromedicine. 2007;12(1):17-25.

9. Alavanja M, Hoppin J, Kamel F. Health effects of chronic pesticide exposure: cancer and neurotoxicity. Annu Rev Public Health. 2004;25:155-197.

10. Calvert GM, Karnik J, Mehler L, et al. Acute pesticide poisoning among agricultural workers in the United States, 1998-2005. Am J Ind Med. 2008;51(12):883-898

11. Tan BLL, Mustafa AM. The monitoring of pesticides and alkylphenols in selected rivers in the State of Selangor, Malaysia. Asia Pac J Public Health. 2004;16:54-63. 
12. Szmedra P. The health impacts of pesticide use on sugarcane farmers in Fiji. Asia Pac J Public Health. 1999;11(2):82-88.

13. Prihartono N, Kriebel D, Woskie S, et al. Risk of aplastic anemia and pesticide and other chemical exposures. Asia Pac J Public Health. 2011;23(3):369-377.

14. Robson MG, Hamilton GC, Siriwong W. Pest control and pesticides. In: Frumkin H, editor. Environmental Heath from Global to Local. San Francisco: Jossey-Bass; 2010:591-634.

15. Envocc.org [homepage on the Internet]. Bureau of Occupational and Environmental Disease, Public Health Ministry, Occupational and Environmental Disease of Thailand in 2006-2008. Bangkok: Bureau of Occupational and Environmental Diseases; 2009. Available from: http://www.envocc.org $/ \mathrm{html} /$ modules.php? name=Downloads\&d_ op=viewdownload\&cid=2. Accessed June 9, 2009. Thai.

16. Siriwong W, Thirakhupt K, Sitticharoenchai D, et al. A preliminary human health risk assess ment of organochlorine pesticide residues associated with aquatic organisms from the Rangsit agricultural area, central Thailand. Human Ecol Risk Assess. 2008;14(5): 1086-1097.

17. Becker, MH, Radius SM, Rosenstock IM, Drachman RH, Schuberth KC, Teets KC. Compliance with a medical regimen for asthma: a test of the health belief model. Public Health Rep. 1978;93(3):268-277.
18. Glanz K, Rimer BK, Lewis FM. Health Behavior and Health Education: Theory, Research, and Practice. San Francisco: Wiley and Sons; 2002.

19. Arcury TA, Quandt SA, Russell GB. Pesticide safety among farmworkers: perceived risk and perceived control as factors reflecting environmental justice. Environ Health Perspect. 2002;110(Suppl 2): 233-240.

20. Salvatore AL, Bradman A, Castorina R, et al. Occupational behaviors and farmworkers' pesticide exposure: findings from a study in Monterey County, California. Am J Ind Med. 2008;51(10):782-794.

21. Mburu F, Boerma JT. Community-based health care 10 years post Alma Ata. Soc Sci Med. 1989;28(10):1005-1006.

22. Spradley JP. The Ethnographic Interview. Austin: Holt, Rinehart and Winston; 1979.

23. Holmes SM. An ethnographic study of the social context of migrant health in the United States. PLoS Med. 2006;3(10):e448.

24. Janhong K, Lohachit C, Butraporn P, Pansuwan P. Health promotion program for the safe use of pesticides in Thai farmers. Southeast Asian J Trop Med Public Health. 2005;36(Suppl 4): 258-261.
Risk Management and Healthcare Policy

\section{Publish your work in this journal}

Risk Management and Healthcare Policy is an international, peerreviewed, open access journal focusing on all aspects of public health, policy, and preventative measures to promote good health and improve morbidity and mortality in the population. The journal welcomes submitted papers covering original research, basic science, clinical \& epidemio-

\section{Dovepress}

logical studies, reviews and evaluations, guidelines, expert opinion and commentary, case reports and extended reports. The manuscript management system is completely online and includes a very quick and fair peerreview system, which is all easy to use. Visit http://www.dovepress.com/ testimonials.php to read real quotes from published authors. 